\title{
0 discurso coletivo de ex-hanseniano morador de um antigo leprosário no nordeste do Brasil ${ }^{*}$
}

\author{
Ana Carolina Rocha Peixoto Rocha ${ }^{1}$ \\ Fátima Luna Pinheiro Landim² \\ Andrea Caprara ${ }^{3}$ \\ Ana Lefèvre ${ }^{4}$ \\ Fernando Lefèvre ${ }^{5}$
}

ROCHA, A.C.R.P. et al. The collective discourse of a former Hansen's disease patient living in an old colony in northeastern Brazil. Interface - Comunic., Saude, Educ., v.15, n.36, p.213-23, jan./mar. 2011.

This study aimed to learn about the discourse on the life of former Hansen's disease patients who lived in an old Hospital Colony. This qualitative study is characterized as a descriptive-exploratory research. The data were collected through semi-structured interviews with 12 subjects and were organized by means of the Collective Subject Discourse technique, which produced the following core insights: "There is a difference between how it was before and how it is now" and "For somebody left with sequels, nothing changes". It was found that the perception of cure was controversial as some patients regarded it as a victory, that is, the fact of being free of the disease allows them to think of (re)starting their lives.

Keywords: Hansen's disease. Leprosy. Collective Subject Discourse. Social history of the disease.
Este estudo teve como objetivo conhecer o discurso acerca da vida de ex-hansenianos residentes em um antigo hospital-colônia. De abordagem qualitativa, caracteriza-se como uma pesquisa descritivo-exploratória. Os dados foram levantados com 12 sujeitos por meio de uma entrevista semiestruturada e foram organizados pela técnica do Discurso do Sujeito Coletivo, obtendo-se as seguintes ideias centrais: "Existe uma diferença entre o antes e o que é hoje e "Para a pessoa que tem sequela, não muda nada". Constatou-se que a percepção da cura da doença foi objeto de controvérsias, havendo os que a percebem como uma vitória, ou seja, o fato de não ter mais a doença lhes possibilita pensar em um (re)começo.

Palavras-chave: Hanseníase. Lepra. Discurso do Sujeito Coletivo. História social da doença.

\footnotetext{
* Elaborado com base em Peixoto (2008); pesquisa financiada pela Fundação de Apoio à Pesquisa (Funcap) e aprovada pelo Comitê de Ética da Universidade de Fortaleza.

${ }^{1}$ Doutoranda em Saúde Coletiva, Universidade Estadual do Ceará. Rua Monsenhor Bruno, 2428, apto. 202, Aldeota. Fortaleza, CE, Brasil. 60.115-191.

anacarolinarochapeixoto@ yahoo.com.br

${ }^{2}$ Mestrado em Saúde Coletiva, Universidade de Fortaleza.

${ }^{3}$ Doutorado em Saúde Coletiva, Universidade Estadual do Ceará.

${ }^{4}$ Doutorado em Saúde Pública, Universidade de São Paulo (USP).

${ }^{5}$ Doutorado em Saúde Pública, USP.
} 


\section{Introdução}

De acordo com Goffman (1988), com o tempo, a representação da lepra auferiu significados bem mais conotativos, passando a reunir mais valores do que a própria sintomatologia da doença. Em especial, esse fato ocorre pela abordagem nos textos bíblicos, que suscita pensamentos místicos acerca da doença: o termo bíblico é utilizado para denominar não só alterações na pele, mas, sobretudo, impurezas na alma, pecados morais e castigos divinos.

Autores da atualidade, como Cunha (2005), Nascimento (2005), Edit (2004), Galvan (2003), Cunha (2002) e Claro (1995), que desenvolveram estudos sobre a história da hanseníase, especificamente em alguns estados brasileiros, observam que a lepra da Bíblia não pode ser comparada e/ou considerada a mesma hanseníase de hoje. Isso faz refletir acerca da existência de uma linha divisória entre estas duas doenças, marcadas por contextos sociais, históricos e culturais diversos.

As representações sociais, entretanto, que avançaram pelos séculos exerceram, e ainda exercem, forte influência sobre os dois conceitos na contemporaneidade (Kovacs, Feliciano, 1997). De tal forma que, para as pessoas doentes de hanseníase submetidas ao isolamento em hospitais-colônias, é quase impossível permanecerem imunes aos preconceitos oriundos das representações, assim como das metáforas constituídas em torno da lepra (Sontag, 1984).

O isolamento das pessoas com lepra é visto, pois, como fator para sustentar, e até ampliar, os mitos em torno da doença, bem como para repercussões socioculturais negativas (Goffman, 1988).

A comprovação de um caráter infectocontagioso é o que faz surgir o isolamento do enfermo como medida para a extinção do mal, incentivando a adoção de um modelo de tratamento baseado no cerceamento da liberdade em grandes instituições de isolamento (Mattos, Fornazari, 2005). Esse fenômeno é também lembrado por Foucault (1999, p.175): "a lepra suscitou modelos de exclusão, os quais acabaram por instituir as formas de isolamento do doente da sociedade".

No campo da Saúde Pública, o fenômeno lepra atingiu seu ápice nas décadas de 1930 e 1940, com a criação dos hospitais-colônias (leprosários) e a instituição da campanha da "profilaxia da lepra" (Pachá, 2008). As colônias foram, então, construídas com o intuito de excluir as pessoas doentes - por meio de internamento compulsório - do convívio social, evitando endemias.

Foi no ano de 1927 que o "Brasil Médico" publicou a notícia da proposta de construção de um leprosário no estado do Ceará, Brasil - com cerca de 400 hectares de terra, sendo vinte hectares construídos: 69 casas individuais, uma enfermaria masculina, uma enfermaria feminina, um pavilhão misto, e outros. Foi uma doação feita por um grande industrial, o coronel Antônio Diogo. O coronel propôs construir com até cem contos de réis e doar mais três contos mensais para sua manutenção (Barbosa, 1994).

Surge, assim, em 9 de agosto do ano de 1928, a colônia Antônio Diogo. Construída no atual distrito de Antônio Diogo, município de Redenção, Ceará, em seu início, a colônia foi conhecida pela denominação de Leprosário Canafístula - expressão adotada em analogia à presença de grande quantidade de plantações de cana-de-açúcar nas suas adjacências.

Quando os primeiros hansenianos chegaram às instalações da Colônia Antônio Diogo, ainda no ano de 1928, os vínculos com a sociedade que conheciam foram abruptamente desligados. O doente era obrigado a se recolher à Colônia, proibido de viver junto aos familiares e amigos, não podendo estudar ou trabalhar fora dos seus limites nem servir ao exército, tirar carteira de identidade, dentre outras convenções sociais.

Em sua maioria, os moradores foram admitidos à antiga Colônia ainda quando crianças. Há relatos de pessoas que viram seus pais pela última vez quando tinham dez anos de idade. As suas redes sociais passavam, assim, por momento de desconstrução.

Mas era importante iniciar novo ciclo (Maffesoli, 2005). E, uma vez cerrados os portões, essas pessoas eram obrigadas a reconstituir suas redes pessoais nos limites demarcados pelos muros da Colônia - onde brincaram, namoraram, casaram, tiveram filhos.

Com o advento da cura, o isolamento e o internamento compulsório das pessoas com hanseníase passam a fazer parte do passado. Desde o início da última década do século passado, o leprosário 
passou a denominar-se Colônia Antônio Diogo. Abriram-se os portões e, juntamente com isso, veio a mudança na rotina, reconquistando, os internos, o direito: de ir e vir, de receber visitas, de retomar ou assumir papéis na sociedade e frequentar os espaços sociais em geral.

Destarte, como foi no passado, nos dias atuais, a antiga Colônia continua atraindo atenções em função da hanseníase e dos hansenianos. São registrados interesses por parte de pesquisadores do mundo inteiro, que, anualmente, chegam à Colônia Antônio Diogo para realizar estudos. O lugar é muito propício ao desenvolvimento desses estudos, em função das pessoas que lá permanecem, bem como de toda a história preservada, seja na memória das pessoas, seja por meio de documentos e estruturas físicas mantidas originais até hoje.

O interesse e a curiosidade despertados favorecem também visitas e doações as mais diversas: mãode-obra para o cuidado com doentes e a promoção de eventos/comemorações festivas; doações de remédios, roupas, cestas básicas, brinquedos, utensílios e aparelhos de uso doméstico. Mantém-se um calendário dominical, em função do qual as mais variadas congregações religiosas se revezam em visitas, ações e doações.

É, muito provavelmente, pela presença de idosos e de dependentes funcionais que se justifica a permanência do voluntariado e das doações. Há percentual significativo de pessoas com sequelas (39,69\% de toda a população) entre as que portaram hanseníase. Também existem os muito idosos e aqueles a quem à idade já se soma a demência. Para a realidade de alguns desses, a dependência instalada torna indispensável o cuidado permanente, em especial por parte de profissionais de saúde. A maioria deles não reside em casas, ocupando o pavilhão ou as enfermarias, locais onde o cuidado diário está favorecido.

Do exposto, considera-se um fenômeno instigante o que está a envolver a Colônia Antônio Diogo (CAD) nos dias atuais: mesmo com os portões do antigo "leprosário" abertos, sofrem as pessoas de estímulos tais (intrínsecos e extrínsecos a elas) que não lhes permitem afastar-se e, muito menos, ir embora. Ao contrário, optam pelo antigo espaço de reclusão, mesmo desejando e mantendo contato com as pessoas de fora daquela comunidade a que passaram a "pertencer".

Há os que, em vez de retornarem às suas residências, ao convívio da família e dos antigos vizinhos, foram buscar lá fora seus familiares, trazendo-os para morarem junto a eles. Essa prática cresceu em tais proporções que, na atualidade, mais da metade das pessoas da colônia nunca portaram a doença. São filhos, netos, esposas, agregados de ex-hansenianos que adotaram para si o estilo de vida característico dos moradores da CAD - mesmo não carregando consigo o histórico da hanseníase (que fala de uma dívida social para com os que foram excluídos), vivem das aposentadorias e pensões asseguradas aos seus pais e avós, das concessões governamentais, da caridade, das doações e ações de voluntários.

Percebe-se que, enquanto os olhares de fora (visitantes e pesquisadores que frequentam o lugar, por exemplo) são direcionados para sensibilizar e aderir aos atos de caridade e escrever teses sobre a necessidade de se "acabar com o estigma e o preconceito", a pessoa dentro da CAD parece ter um movimento contrário, que é o de manter viva a sua história, assumir essa identidade, afirmar-se hanseniano, dependente (portanto) e, com isso, deixar clara a demarcação, inclusive, do espaço físico conquistado (a Colônia), separando-os, mesmo que simbolicamente, do resto da sociedade.

Os fatos mencionados despertaram o interesse de estudar a atitude desses atores sociais, ficando, assim, posto um desafio epistemológico: penetrar o cerne da forma de socialidade nascente e tomar uma atitude diante dessa nova relação com os outros; o que, nos dias de hoje, Maffesoli (2005) atualiza como se tratando de algo que desarruma os modos de pensar mais tradicionais.

A liberdade de atitude, todavia, reclama uma tomada de distância em relação aos sistemas causais mais simplistas, para bem captar a realidade. É necessário, ainda, não continuar prisioneiro dos metadiscursos ou das certezas sistemáticas e apriorísticas, passando a investigar a rede de narrativas como campo de construção dos sentidos comuns a uma rede social mais ampla. Nesse campo, não se pode esquecer Sluzki (1997) quando escreve ser o foco da atenção o compartilhamento de histórias, descrições, valores e relatos que fazem referência aos aspectos particulares da rede pessoal.

Mobilizados por esse intuito, estabeleceu-se o objetivo de: conhecer o discurso acerca do que é ser ex-hanseniano residente de um antigo hospital-colônia. 


\section{Metodologia}

O estudo seguiu pressupostos da metodologia de Análise das Redes Sociais (ARS). O histórico de aplicação dessa metodologia recupera três principais vertentes. A elaboração de um sentido analítico voltado para as redes sociais na primeira vertente vem com os analistas sociométricos, tendo, como principal representante, Jacob Moreno, psicólogo remanescente da teoria da Gestalt (Meneses, Sarriera, 2005; Silva, 2003).

A segunda vertente reúne, na Universidade de Harvard, antropólogos, psicólogos e sociólogos australianos, dentre os quais se destacam W. Lloyd Wamer e Elton Mayo: os primeiros pesquisadores a usarem sociogramas, adaptando os diagramas para descrever como se estruturavam as relações interpessoais informais dos trabalhadores das fábricas em pequenas comunidades americanas (Silva, 2003; Portugal, 1995; Troncoso, Alvarez, Sepúlveda, 1995).

Na terceira vertente, que desembocaria na moderna ARS, encontram-se nomes como John Barnes, Clyde Mitchell e Elizabeth Bott, antropólogos sociais de Manchester que aplicaram a sociometria ao problema do apoio social disponível para indivíduos em situação de estresse, poder, conflitos e mudanças. Com o método utilizado, os pesquisadores iniciaram na perspectiva de sistematizar arcabouço teórico para descrever qualitativamente os sistemas vivos em relações complexas (Silva, 2003; Troncoso, Alvarez, Sepúlveda, 1995).

Escreve Pérez (2006) que o campo da ARS diferencia-se de outras disciplinas de cunho social, quando não são teorizados os grupos humanos como os blocos de construção da sociedade. É que, na prática, esse tipo de abordagem está aberto a estudar desde os menores sistemas sociais delimitados a partir das comunidades até ligações entre websites. Em vez de tratar os indivíduos - aqui entendidos não só como pessoas, mas também organizações, estados etc. - como unidades de análise, esta (a análise) incide sobre a forma como a estrutura, ou seja, a quantidade de nós e de ligações entre eles, a composição, a localização dos nós, dentre outros, afetam a dinâmica da rede (Scott, 2000; Wasserman, 1994; Wellman, 1991).

Definida por Freeman $(2006,2004)$ como a abordagem estrutural baseada no estudo da interação entre os atores sociais, chamada de análise de redes sociais, a ARS efetivamente traduz um método de aproximação com a estrutura relacional (nível mais macro da rede) e com as características mais comportamentais dos atores sociais (nível micro). De maneira que o que define o caráter assumido pelo método, hoje, são: o fenômeno estudado, a perspectiva adotada, as metodologias e ferramentas utilizadas.

No delineamento da metodologia, adotou-se o proposto por Sluzki (1997) para análise da rede pessoal e de narrativas - definida como o campo das vivências comuns às pessoas, famílias ou coletividade, em que se busca registrar os discursos encaixados em espaço de tempo contextualizado e histórico.

O estudo foi realizado durante os anos de 2007 a 2008, na antiga Colônia de Hansenianos, atual Centro de Convivência Antônio Diogo (CCAD), junto a 12 pessoas, dentre aquelas remanescentes do internamento compulsório.

Como parte da metodologia, no primeiro momento, o levantamento de campo contemplou os 96 moradores do CCAD, registrados como ex-hansenianos. Objetivou-se identificar as centralidades da rede pessoal familiar e de amizade, direcionando-se as entrevistas ulteriores.

Para a medida de centralidade, aplicou-se um questionário adaptado de Silva (2003), denominado, por esse autor, como gerador de nomes - por se destinar ao levantamento dos principais nomes que exercem forte influência na dinâmica da rede social estudada. O questionário originário foi desenvolvido para a realidade das redes sociais informais intraorganizacionais; daí ter sido realizada uma adaptação, tornando-o pertinente às características do grupo e ao objeto desta investigação.

Durante a aplicação daquele instrumento, estipulou-se o número máximo de três pessoas para serem citadas por parte de cada informante. O propósito foi favorecer a análise, na medida em que se restringiu o número de citados como participantes da rede às pessoas que, de fato, tinham grande expressão para o estudo em andamento. 
Para calcular as medidas de centralidade, foi utilizado o programa computacional UCINET, versão 6.123 (Borgatti, Everett, Freeman, 2006). As exatas etapas de todo esse processo podem ser assim sintetizadas: em seguida à devolução dos questionários, codificamos os nomes gerados pelos atores estudados em AT1, AT2, A., inserindo os dados, em seguida, no software. Por meio de cálculos matriciais, o UCINET forneceu os índices de centralidade (o de grau de entrada e o de Bonacich), que representam os indicativos dos atores que assumem os papéis de conectores centrais na rede. O cálculo da centralidade permitiu, dentre outras inferências, a identificação dos atores que foram reconhecidos como desempenhando importante papel de ajuda na rede estudada.

As entrevistas foram, assim, direcionadas aos sujeitos que exerciam centralidade na rede social de amizade e pessoal familiar dos ex-hansenianos. A estes foi aplicada a questão geradora: o que significa ser (ex-)hanseniano para o(a) Sr(a). nos dias de hoje? Na condução da técnica, pautou-se pela referência da Spink (2000), que compreende a entrevista como prática discursiva por meio da qual se produzem sentidos e se fazem versões da realidade, e nos pressupostos de elaboração e aplicação das questões de entrevistas propostos por Leopardi (2001).

A organização dos dados apoiou-se na técnica do Discurso do Sujeito Coletivo, em acordo com o preconizado por Lefèvre e Lefèvre (2005). Trata-se de uma forma de representar a opinião coletiva por meio de uma série de discursos, pensamentos, ideias ou posicionamento sobre um dado tema presente em determinada formação sociocultural. Como estratégia metodológica, visa tornar mais clara a expressão de uma dada "figura", ou seja, a representação social sobre um fenômeno vivenciado.

A título de sustentação teórica, quando a técnica tende a afirmar o pensamento individual como representação do que pensa a coletividade, os autores expressam o pensamento coletivo como a presença internalizada - no pensar de cada um dos membros da coletividade - de esquemas sociocognitivos ou de pensamento socialmente compartilhado. Para obter o pensamento coletivo, é preciso, portanto, convocar os indivíduos, um a um, para exporem seu pensamento social internalizado, livre de pressão psicossocial do grupo. O conjunto dessas individualidades opinantes pode representar, sociologicamente, uma coletividade.

Para tanto, o DSC usa a categoria pelo método da indução, ou seja, analisa as discussões do grupo e trabalha por temas ou assuntos, dos quais são retiradas as figuras metodológicas ou conceitos operativos e metodológicos, que são: Expressão-chave (Ech), Ideia Central (IC), Ancoragem; todas usadas para se processarem os depoimentos e se obterem, ao final, os Discursos do Sujeito Coletivo (DSC).

A análise envolvendo os conceitos de estigma e instituição (total) fundamentou-se em obras, dentre as quais se destacam as de Erving Goffman - Estigma: a identidade deteriorada; Manicômios, prisões e conventos.

Os princípios éticos preconizados pela resolução 196/96, do Conselho Nacional de Saúde, foram atendidos; tendo recebido aprovação do Comitê de Ética em Pesquisa.

\section{Resultados}

Dois DSC foram organizados em função das respostas dadas ao seguinte questionamento: "O que significa ser ex-hanseniano nos dias de hoje?".

No primeiro, em função da IC A - existe uma diferença entre o que era antes e o que é hoje -, cinco ex-hansenianos coincidem em suas representações, editadas no discurso transcrito no Quadro 1. 
Quadro 1. IC A - Existe uma diferença entre o que era antes e o que é hoje

“Pra mim, ser ex-hanseniano hoje é uma coisa muito boa. Muito mesmo! Porque acabou aquele tabu: Ah! Essa ai tem lepra, ou foi leprosa... Antigamente, as pessoas tinham pavor, os próprios pacientes se camuflava, se isolava do mundo. Quando é que um sadio iria fazer curativo em um doente? Mas, hoje em dia é raro encontrar uma pessoa para ter pavor. Porque, com esse novo tratamento, o pessoal acredita na cura. Isso significa que a gente não tem mais a doença. Isso é muito importante. Hoje eu não tenho tantos problemas não em ser ex-hanseniano. Então, existe uma diferença muito grande do antes para hoje: por mais mutilado que o paciente seja ele quer é aparecer; os pacientes entregam os seus pés pros profissionais e não tão nem ai pro azar...".

Tendo em mente esse DSC, ressalte-se, inicialmente, que, em Goffman (1988), encontra-se a descrição de estigma como uma criação social, reforçada, inclusive, pelos próprios estigmatizados quando tendem a partilhar das representações que os isolam, os classificam de indesejáveis e os desvalorizam como pessoas.

Assim é que as diferenças de identidade social vão sendo, em princípio, estabelecidas como algo externo ao indivíduo, mas gradativamente incorporadas, levando o sujeito a ser reconhecido e se reconhecer não como uma individualidade, mas segundo características típicas da classe do estigma: com determinações que passam a sinalizar os desvios (de conduta esperada) e a reger, portanto, suas relações com o meio. Os ex-hansenianos participantes desse estudo denotam consciência de sofrer desse fenômeno, identificado, nos escritos de Goffman (1993), como "categorização". É o que transparece a representação: "[...] acabou aquele tabu: Ah! Essa aí tem lepra, ou foi leprosa [...]. Antigamente, as pessoas tinham pavor, os próprios pacientes se camuflavam, se isolavam do mundo. Quando é que um sadio iria fazer curativo em um doente?".

Alguns acontecimentos históricos vão, todavia, permitir uma (re)categorização dessas pessoas. Dentre estes, a descoberta de medidas efetivas contra o bacilo, fazendo com que a hanseníase seja uma doença que, uma vez tratada, apresente possibilidades significativas de cura e não traga risco de contágio, bem como a existência de pessoas mais bem esclarecidas faz atualizar o comportamento social diante da doença e do doente.

Também é fato que a hanseníase não representa, atualmente, uma emergência sanitária, o que leva a um redirecionamento de algumas posições políticas e sociais no que diz respeito às formas patológicas mais virulentas e agudas. De modo particular, no Brasil, as atenções se transferiram muito, por exemplo, para o fenômeno da aids. Isso não implica, todavia, um descuido para com a incidência. Sobretudo nos lugares em que a doença ainda é endêmica, há, de modo continuado, como é na realidade das pessoas do CCAD, uma vigília, e mantêm-se as modalidades de assistência e de cuidados às pessoas doentes, como às curadas que apresentem alguma sequela.

Arrisca-se, pois, a dizer que os ex-hansenianos deste estudo já vivenciam uma outra face do mesmo fenômeno "estigma". Nesta, a autoimagem e a identidade - sempre dependentes do olhar de fora, ou seja, da ideia que os demais fazem dele, das formulações ou convenções sociais - parecem sofrer de uma atualização, no cerne da qual se abre espaço para dar a entender que a pessoa reconhece e reage ao estigma de que sofre, por percebê-lo ruim. Nesse sentido é que Goffman (1988) alerta para o movimento espontâneo que o estigmatizado faz na direção de reduzir o estigma e as "tensões" que tornam difícil para si e para o outro o cotidiano na presença deste.

Destarte, na tentativa de desfocar a atenção da sociedade da origem do estigma, concorda-se que nem sempre esse movimento é, em tudo, positivo para o ex-hanseniano, de maneira que é possível acreditar nele como favorecendo outros rótulos: o de dependente, necessitado ou coitadinho, como exemplos. Deve existir, no meio de tudo - e como prevê Goffman (1988) - um certo esforço, da parte do ex-hanseniano, para que ele ou a sua doença não apareça muito mais do que as necessidades que acumula.

Por outro lado, ao insistir em não deixar o antigo espaço de confinamento, leva a crer numa internalização do estigma construído ao longo dos anos, reificando a construção social do que é ter sido 
um leproso. No que se refere ao caráter subjetivo (não ignorando o objetivo), constata-se prevalecer o peso da marca trazida pela institucionalização e defende-se que a influência dessa marca só desaparecerá com muito ônus para os que a vivenciaram.

Ouvindo e lendo a história do antigo leprosário, atual CCAD, constata-se como os seus ciclos não fugiram à destruidora força simbólica das instituições totais (Goffman, 2001): com início na instituição reservada para pessoas consideradas uma ameaça à comunidade, passando a um lugar para cuidar das pessoas incapazes e inofensivas, até um espaço que serve de refúgio do mundo por muito tempo desconhecido e, portanto, ameaçador.

A clausura, como a tutela, é, portanto, iatrogênica, ocasionando, no mínimo, o medo de enfrentar o mundo ameaçador, a "desproteção" verificada fora dos portões do CCAD. Isso é o que também pode implicar uma quase teatralização, identificando-se o ex-hanseniano e buscando, muitas vezes, afirmar e reafirmar sua condição de doente. Ratificam essa afirmaçãa inferências e posturas como as descritas no DSC: "[...] ser ex-hanseniano hoje é uma coisa muito boa [...]. Por mais mutilado que o paciente seja, ele quer é aparecer; os pacientes entregam os seus pés pros profissionais e não tão nem aí pro azar [...]"

O teórico Michael Maffesoli (2005) oferece um prisma de leitura que atualiza essa condição quando escreve que esse tipo de movimento pode também ser reconhecido como técnica de demarcação do espaço para pertencer; uma forma de (re)construção da identidade, e de resistência, portanto, ao estigma sofrido. Reaparece, por meio desta, a força antropológica da dimensão do espaço: o que me liga à terra é vetor de socialidade.

Como isso se dá? Tornou-se importante para o ex-hanseniano manter viva a história pessoal como forma de estabelecer, com outros, similaridades/igualdades e assumir, assim, uma identidade. Isso é o que pode ajudar também na identificação com um grupo e no fortalecimento do vínculo com um lugar que é reconhecido como sendo deles, destinado aos que são iguais. Um lugar demarcado para pertencer, assim como a criação da identidade rejeita a categorização vinda de fora, inscrevendo a ordem, a autonomia e a (auto) referência para voltar a "ser" em um contexto de grupo social (Maffesoli, 2005).

No segundo DSC apresentado no Quadro 2, foram editados em função da IC B - para a pessoa que tem sequela não muda nada - os depoimentos de sete ex-hansenianos, que ajudaram a compor a representação do que é ser hanseniano no contexto do CCAD.

O sistema de valores mais geral da sociedade perde força na medida em que a identidade do exhanseniano, como grupo social, se torna mais evidente. Não obstante, Goffman (1993) afirma que, na maioria das situações, as identidades individuais serão sempre marcadas pela diferença; no caso do grupo aqui estudado, pelas deformidades.

Quadro 2. IC B - Para a pessoa que tem sequela não muda nada

\footnotetext{
"Para mim ser ex-hanseniana nos dias de hoje não tem muita diferença não! Para a pessoa que tem seqüela, eu acho, que não muda nada! Na verdade, isso (a cura) é bom para quem está em bom estado. Pois, em cima do mutilado, do sequelado existe, sim, o preconceito. É como ser um ex-presidiário, é como ser um ex (silêncio) de algo forte que jamais se apaga. Ainda existe muito preconceito, e isso me incomoda muito. Quando eu vou para redenção e a pessoa pergunta: de onde você é? Se eu digo que sou de Antônio Diogo, ou da colônia, não são todos, mas tem uns que se afastam, tem uns que tem cisma da gente. Sinceridade, ai como tem! No meu caso, como a minha seqüela foi só nessa mão (tem a mão em garra) quando estou lá fora e as pessoas me perguntam eu digo que foi devido à paralisia infantil. Eu não preciso dizer que foi devido à doença. Porque tem até hospital que não aceita. Às vezes, a gente chega no hospital, quinem eu fui operar esse dedo, e só em as pessoas saberem que somos daqui (da colônia) já ficam com receio por que não acreditarem na cura. Por isso que Antônio Diogo (o CCAD) é o meu lugar. Se eu fosse morar em outro lugar eu não me sentiria bem, como eu me sinto aqui. Aqui eu ainda me sinto a vontade. Às vezes, quando eu vou para igreja, porque a gente vai quando tem encontro dos ministros, eu só me sinto bem porque estou na casa de Deus. Eles me tratam bem, mas eu não fico a vontade como eu fico aqui dentro. Mas, eu vou ser sincera (silêncio) antes era melhor do que hoje: porque tinha mais irmãos doentes. Era quase todos, né? Ficávamos mais a vontade. Você entende?".
} 
No que deixa transparecer o DSC, apesar dos esforços e do momento de evolução histórica da ciência, ainda persiste uma situação de estigma em relação ao doente, muito mais do que à doença hanseníase. São as marcas, as deformidades que incomodam.

O conceito de estigma é desenvolvido por Goffman (1988) como um fenômeno social que pode ser constatado com base em, pelo menos, uma dentre três manifestações culturais possíveis: as abominações do corpo, os defeitos de caráter e a proveniência social. No caso da hanseníase no Brasil, Queiroz e Carrasco (1995) defendem a posição de que o estigma guarda estreita relação com as deformidades físicas do paciente, uma espécie de abominação a estas deformidades, levando à representação cultural de inferioridade da pessoa, de desqualificação diante das demandas da vida cotidiana.

O rótulo, pois, de leprosa, como foi no passado, ou hanseniana, como é no presente, situa a pessoa na posição de desvantagem, de descrédito, com a consequente marginalização social. Resta ao exhanseniano "ou se adequar ao papel marginal a ele designado, ou tentar 'encobrir' as marcas que caracterizam o estereótipo estigmatizante" (Queiroz, Carrasco, 1995, p.485). Essas duas práticas podem ser atestadas como em uso pelos depoentes do DSC.

Adequar-se ao papel marginal leva, por exemplo, os depoentes a elaborarem um discurso de descrença na possibilidade de serem comparados a "uma pessoa qualquer". Admitem que as marcas (visíveis e invisíveis) que a doença deixou não podem e não são ignoradas. Elas atribuem, entretanto, ao olhar de fora todo o preconceito ainda existente em relação aos hansenianos.

Há, todavia, por parte dos próprios ex-hansenianos, uma incorporação do (pre)conceito social. Eles ignoram, mas passam a reproduzir o comportamento (de reclusão) esperado, bem como o discurso preconceituoso de que eles são diferentes. Ao refletir sobre o tema, vem à mente, inclusive, um trecho do que escreveu Leonardo Boff (1997, p.35), em "A águia e a galinha": "[...] o martelamento era tanto que muitos colonizados acabaram hospedando dentro de si os colonizadores com seus preconceitos. Acreditavam que de fato nada valiam. Que eram realmente bárbaros [...]".

O "estigma" na realidade do ex-hanseniano ainda é forte determinante de restrições (e autorrestrições) dos espaços públicos em que é ou não permitida a sua permanência ou, até, circulação. Traduz, essencialmente, a deterioração da imagem (Goffman, 1993), com consequente rejeição social à marca que passa a identificar essa pessoa: sua deformidade e mutilações.

A deterioração da imagem também decorre de certa manipulação da informação, o que, de acordo com Goffman (1988), divide geograficamente o espaço social. O discurso coletivo nos coloca, assim, diante da realidade de que em nossa sociedade existem lugares públicos onde não se espera ou não se deseja a presença, ficando moralmente pactuada a proibição de acesso para os "defeituosos" - que podem ser representados por certos grupos raciais, religiosos ou étnicos; as prostitutas; os bêbados; os loucos; os hansenianos etc. E a rejeição que os ex-hansenianos passam a sofrer está implicada com o seu desconhecimento ou simples "desrespeito" a esse controle social que, à luz de Goffman, traduz a moralização dos espaços.

Ora, mas se considerarmos que esses espaços também são palcos de diversos conflitos, na luta para assegurar direitos e garantir a sobrevivência, isso explica, ainda, o estigma do ônus da moralidade que empregamos para manter não só os ex-hansenianos, como também outras minorias afastadas das diversas linhas de competição (Goffman, 1993); sendo esta uma motivação real (inconsciente) para que o ex-hanseniano seja evitado, visto como uma ameaça. Do exposto, reflete-se, inclusive, acerca dessa postura como um desafio para a política de reinserção social dos contingentes estigmatizados - é o caso de lembrar as políticas voltadas para a pessoa com transtorno mental e aquela com necessidades especiais, como exemplos. 


\section{Considerações finais}

Nos dias atuais, o CCAD é habitado por ex-hansenianos e familiares, todos desfrutando de um mesmo cotidiano. Poucos foram os pacientes que retomaram a sua vida longe do antigo leprosário, e ainda há aqueles que saíram e depois retornaram por não terem conseguido reconstruir a sua vida "lá fora".

Constata-se que o espaço da Colônia, ao longo desses anos, também passou por alterações, assim exigindo, dos seus moradores, uma forçada adaptação a uma nova política de funcionamento, às novas necessidades e aos novos moradores. Pode-se concluir que a resistência percebida em assumir essas mudanças, abandonando o estigma e voltando às suas vidas, decorre do "atrofiamento", uma condição iatrogênica consequente às instituições totais.

No tempo em que adentraram a Colônia, as verdades científicas apontaram o isolamento como a alternativa viável e mais adequada para se enfrentar a endemia hansênica. De seu lado, os exhansenianos vivenciaram o isolamento, junto com a tutela de suas vidas e as medidas disciplinares para os desvios de conduta. Não lhes permitiram desenvolver, fora do que intuitivamente sabiam ser e fazer, modos de realizarem a crítica interna aos princípios dessa prática, fundamentalmente anuladora e estigmatizante. Assim é que, simplesmente, incorporaram a lógica predominante nesses locais estabelecidos para cuidar de pessoas consideradas incapazes ou perigosas para a sociedade.

Pode-se dizer que os anos de institucionalização acarretaram a mortificação do eu, significando que o ser "eu" não consegue mais se identificar com o ambiente externo àquele que pertenceu durante parte significativa da vida. Assim é que pode causar medo, ao ex-hanseniano, ir residir fora (da proteção) da Colônia: lugar onde mantém vínculos, assume um papel social e é respeitado/reconhecido por este. Do lado de fora, acreditam, não há mais lugar para eles. Seriam rejeitados, hostilizados pelo fato de carregarem as limitações físicas e as marcas simbólicas da doença e do internamento em leprosário.

O apego ao passado e ao lugar onde morou grande parte da vida, a rede de relações, enfim, do exhanseniano serve, nestas circunstâncias, ao propósito de permitir a identificação com um grupo, favorecendo um vigoroso sentimento de pertença e o fortalecimento de uma autoimagem. Permanecer nos espaços da Colônia, tendo por perto o familiar que o aceita e o colega também ex-hanseniano (com quem se identifica), permite um reconhecimento (e, portanto, aceitação) de si.

A identificação permite a essas pessoas organizarem-se como grupo social-com valores, cultura própria, interesses - que também visa resistir às categorizações vindas de fora. Certamente, esse movimento implicará o fim, ou o enfraquecimento, dos valores gerais dominantes e a redução do estigma.

Quanto à necessidade que o ex-hanseniano tem de alimentar, nos visitantes, práticas de aproximação com a sua comunidade - como é o caso da caridade, da solidariedade e do voluntariado -, considera-se que, ao tempo em que transparece um estado de conformação coletiva e um investimento coletivo na condição de incapaz, de "coitadinho", busca, também, o ex-hanseniano resistir, (re)construindo sua identidade e criando oportunidades para pertencer a um grupo e fortalecê-lo diante dos demais grupos sociais.

Por fim, tem-se em mente que o presente estudo permitiu conhecer a representação de um mundo de vida: o ser ex-hanseniano, habitante de um antigo leprosário. Entretanto, depara-se com as limitações características ao fato de a exploração desse universo necessariamente se dar pela aproximação com as subjetividades, o imaginário que é hoje e não será mais amanhã. Ainda, de tudo que foi exposto, ficam questionamentos que abrem perspectivas para novas investigações: pode-se crer nos ex-hansenianos como formando hoje um grupo social em plena fase de construção e reconhecimento? O antigo leprosário é hoje um espaço que se liberta da força histórica das instituições totais? A chegada das pessoas sadias e a presença constante da sociedade implicam atualização da categoria dos hansenianos, acelerando aquele primeiro fenômeno, quando instaura uma nova ordem: a normalização do ser hanseniano no convívio diário com outras pessoas e grupos sociais? 


\section{Colaboradores}

Ana Carolina Rocha Peixoto responsabilizou-se pela construção da redação, edição e finalização do artigo. Fátima Luna Pinheiro Landim responsabilizou-se pela edição, correção e finalização do artigo. Andrea Caprara, Ana Lefèvre e Fernando Lefèvre responsabilizaram-se pela correção e edição do artigo.

\section{Referências}

BARBOSA, J.P.A. História da saúde pública no Ceará: da colônia Vargas. Fortaleza: Universidade Federal do Ceará, 1994.

BOFF, L. A águia e a galinha: a metáfora da condição humana. 40.ed. Petrópolis: Vozes, 1997.

BORGATTI, S.P.; EVERETT, M.G.; FREEMAN, L.C. UCINET - version 6.123. Natick: Analytic Technologies, 2006.

CLARO, L.B.L. Hanseníase: representações sobre a doença. Rio de Janeiro: Fiocruz, 1995.

CUNHA, A.Z.S. Hanseníase: aspectos da evolução do diagnóstico, tratamento e controle. Cienc. Saude Colet., v.7, n.2, p.235 -42, 2002.

CUNHA, V.S. O isolamento compulsório em questão: políticas de combate a lepra no Brasil (1920-1941). 2005. Dissertação (Mestrado) - Fundação Oswaldo Cruz, Rio de Janeiro. 2005.

EIDT, L.M. Ser hanseniano: sentimento e vivências. Hansen Int., v.29, n.1, p.21-7, 2004.

FOUCAULT, M. Vigiar e punir: nascimento da prisão. 21.ed. Petrópolis: Vozes, 1999.

GALVAN, A.L. Hanseníase-lepra: que relações ainda se mantêm? Canoas: Ulbra, 2003.

GOFFMAN, E. Manicômios, prisões e conventos. São Paulo: Perspectiva, 2001.

Estigma: la identidad deteriorada. 5.ed. Buenos Aires: Amorrortu, 1993.

Estigma: notas sobre a manipulação da identidade deteriorada. 4.ed. Rio de Janeiro: Zahar, 1988.

KOVACS, M.H; FELICIANO, K.V.O. Opiniões sobre a doença entre membros da rede social de pacientes de hanseníase no Recife. Public Health, v.1, n.2, p.112-8, 1997.

LEOPARDI, M.T. Metodologia da pesquisa na saúde. Santa Maria: Pallotti, 2001.

LEFÈVRE, F.; LEFÈVRE, A.M.C. O discurso do sujeito coletivo: um novo enfoque em pesquisa qualitativa (desdobramentos). 2.ed. Caxias do Sul: Educs, 2005.

MAFFESOLI, M. O mistério da conjunção: ensaios sobre comunicação, corpo e socialidade. Porto Alegre: Sulina, 2005.

MENESES, M.P.R.; SARRIERA, J.C. Redes sociais na investigação psicossocial. Porto Alegre: Aletheia, 2005. v.21.

NASCIMENTO, D.R. As pestes do século XX: tuberculose e aids no Brasil - uma história comparada. Rio de Janeiro: Fiocruz, 2005.

PACHÁ, P.H.C. Hanseníase: imposição estatal e isolamento compulsório. Cad. Saude Colet., v.16, n.2, p.327-44, 2008.

PEIXOTO, A.C.R. Rede social: saberes e práticas no cotidiano do ex-hanseniano. 2008. Dissertação (Mestrado) - Universidade de Fortaleza, Fortaleza. 2008. 
PORTUGAL, S. As mãos que embalam o berço: um estudo sobre redes informais de apoio à maternidade. Rev. Crit. Cienc. Soc., n.2, p.155-78, 1995.

As mãos que embalam o berço. As redes informais de apoio à maternidade, Revista Crítica de Ciências Sociais, v.42, 1995.

QUEIROZ, M.S.; CARRASCO, M.A.P. O doente de hanseníase em Campinas: uma perspectiva antropológica. Cad. Saude Publica, v.11, n.3, p.479-90, 1995.

SCOTT, J. Social network analysis: a handbook. 2.ed. London: Thousands Oarks, 2000.

SILVA, M.C.M. Redes sociais intraorganizacionais informais e gestão: um estudo nas áreas de manutenção e operação da planta hyco-8, Camaçari, BA. 2003. Dissertação (Mestrado) - Núcleo de Pós-Graduação, Escola de Administração, Universidade Federal da Bahia, Salvador. 2003.

SLUZKI, C.E. A rede social na prática sistêmica. Trad. Claudia Berliner. São Paulo: Casa do Psicólogo, 1997.

SOTANG, S. A doença como metáfora. Rio de Janeiro: Graal, 1984.

SPINK, M.J. (Org.). Práticas discursivas e produção de sentidos no cotidiano: aproximações teóricas e metodológicas. 2.ed. São Paulo: Cortez, 2000.

TRONCOSO, M.; ALVAREZ, C.; SEPÚLVEDA, R. Redes sociales, salud mental y esquizofrenia: una revisión del tema. Rev. Psiquiatr., v.3, n.4, p.77-85, 1995.

WASSERMAN, S.; FAUST, K. Social networks analysis: methods and applications. New York: Cambridge University Press, 1994.

WELLMAN, B.; BERKOWITZ, S.D. (Orgs.). Social structures: a network approach. Cambridge: Cambridge University Press, 1991.

ROCHA, A.C.R.P. et al. Discurso colectivo de un ex enfermo de Hansen paciente en una leprosería nordeste del Brasil. Interface - Comunic., Saude, Educ., v.15, n.36, p.213-23, jan./mar. 2011.

El objetivo del estudio fue conocer el discurso sobre la vida de (ex) enfermos de Hansen residentes en un antiguo hospital-colonia. Sobre la base de su enfoque cualitativo, este estudio se caracteriza como una investigación descriptiva-exploratoria. Los datos se obtuvieron de una entrevista semi-estructurada con 12 sujetos y fueron organizados por la técnica del Discurso del Sujeto Colectivo, obteniéndose las siguientes ideas centrales: "Hay una diferencia entre cómo era antes y cómo es ahora" y, "Para personas con secuelas, no cambia nada". Se encontró que la percepción de cura de la enfermedad fue objeto de controversias, habiendo los que la perciben como una victoria, es decir, el hecho de ser libres de la enfermedad les permite pensar en recomenzar.

Palabras clave: Enfermedad de Hansen. Lepra. Discurso del Sujeto Colectivo. La historia social de la enfermedad. 